\title{
Studies in Organocatalysts Synthesis for Direct Aldol Reaction
}

\author{
Bruna Miranda Soares, Andréa Maria Aguilar* \\ Universidade Federal de São Paulo \\ Instituto de Ciências Ambientais, Químicas e Farmacêuticas, Departamento de Ciências Exatas e da Terra \\ Diadema - São Paulo \\ *e-mail corresponding author: andrea.aguilar@unifesp.br
}

Keywords: organocatalysis, direct aldol reaction, stereoselective synthesis

\section{INTRODUCTION}

The aldol reaction is one of the most important $\mathrm{C}-\mathrm{C}$ bond forming reactions in organic synthesis, with a large application in the stereoselective synthesis of highly functionalized natural and synthetic substances.

The first intermolecular proline-catalyzed direct aldol reaction was described by List and coworkers in $2000 .^{2}$ Since then, the direct aldol reaction of aldehydes with ketones in the presence of a catalytic amount of L-proline and its structural derivatives have been evaluated for use in asymmetric catalytic direct aldol reactions. ${ }^{3}$

We will report here our preliminary results on the organocatalysts synthesis which will be applied in direct aldol reaction of aldehydes with ketones in aqueous media.

\section{RESULTS AND DISCUSSION}

In this work we planned to synthetize the structural proline derivatives $\mathbf{6 , 8 , 1 0}$, with the aim to test the effect of the pirrolidine ring functional groups on the catalytic performance of stereoselective direct aldol reactions.

The synthetic route to approach compounds 6, 8, 10 was based in literature, ${ }^{4}$ and starts with commercially available trans-4-Hydroxy-L-proline (1) which was converted by conventional methods into the $\mathrm{N}$-Boc protected methyl ester derivative 2, as outlined in Scheme 1.

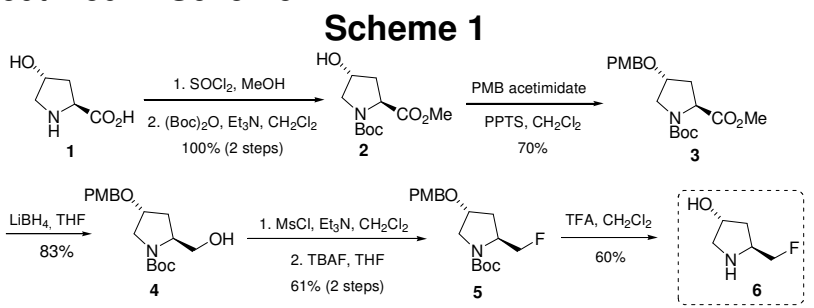

Protection of 2 as the PMB ether, followed by $\mathrm{LiBH}_{4}$ reduction gave alcohol 4 in good yield (58\% yield, 4 steps). After mesylation on the primary alcohol 4, we carried out fluorination protocol using anhydrous TBAF, and under this condition it was possible to isolate the desired compound fluorinated 5 in good yield (61\%, 2 steps). The Boc and PMB groups were removed by treatment of $\mathbf{5}$ with trifluoroacetic acid, and after purification with ion- exchange resin, the desired product $\mathbf{6}$, was obtained in $60 \%$ yield.

Both proline derivatives 8 and 10 were prepared from $\mathrm{N}$-Boc protected methyl ester 2, as showed in Scheme 2.

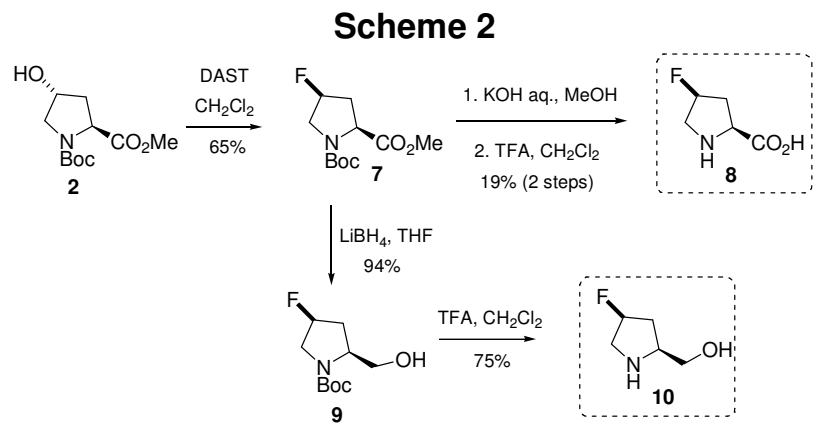

The fluorination of $\mathbf{2}$ was carried out with diethylaminosulfur trifluoride (DAST) which gave the compound 7 in $65 \%$ yield. Saponification of 7 and then removal of the Boc group with TFA afforded compound 8 in 19\% yield (2 steps). Proline derivative 10 was prepared by $\mathrm{LiBH}_{4}$ reduction of 7 which furnished alcohol 9 in good yield ( $94 \%$ yield). Subsequent deprotection of the Boc group using TFA gave the crude product, which was purified with ion exchange resin to give $\mathbf{1 0}$ in $75 \%$ yield.

\section{CONCLUSION}

In conclusion, we have synthesized the proline derivatives $6,8,10$ which will be tested as organocatalysts in cross-aldol reactions of aldehydes with ketones in aqueous media. These experiments are underway in our laboratory with the aim to provide a direct route to aldol adducts in high enantioselectivity and under environmentally acceptable solvent.

\section{ACKNOWLEDGEMENTS}

We are grateful to CNPq, Fapesp and Capes.

\section{REFERENCES}

${ }^{1}$ Dias, L. C., Aguilar, A. M. Chem. Soc. Rev. 2008, 27, 451

2 List, B., Lerner, R. A., Barbas, C. F., III J. Am. Chem. Soc. 2000, 122 2395.

${ }^{3}$ Trost, B. M, Brindle, C. S. Chem. Soc. Rev. 2010, 39, 1600.

${ }^{4}$ a) Rosen, T.; Chu, D. T. W.; Lico, I. M.; Fernandes, P. B.; Marsh, K. Shen, L.; Cepa, V. G.; Pernet, A. G. J. Med. Chem. 1988, 31, 1598. b) Filosa, R.; Holder, C.; Auberson, Y. P. Tetrahedron Lett. 2006, 47, 8929.

$14^{\text {th }}$ Brazilian Meeting on Organic Synthesis $-14^{\text {th }}$ BMOS - September 01-05, 2011-Brasilia, Brazil 